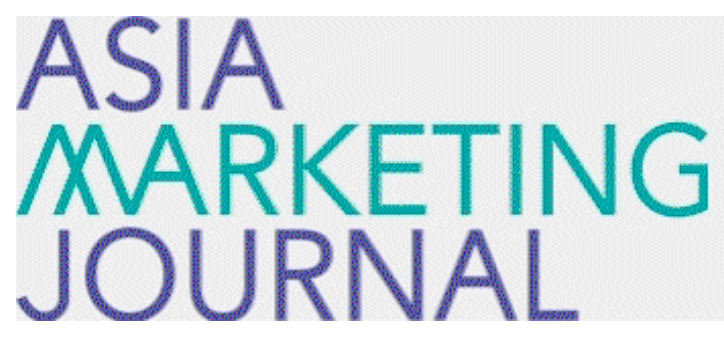

ASIA MARKETING JOURNAL

Volume 18 | Issue 4

Article 6

$1-31-2017$

\title{
A Direct Utility Model with Dynamic Constraint
}

Byungyeon Kim

Takuya Satomura

Jaehwan Kim

Follow this and additional works at: https://amj.kma.re.kr/journal

Part of the Marketing Commons

\section{Recommended Citation}

Kim, Byungyeon; Satomura, Takuya; and Kim, Jaehwan (2017) "A Direct Utility Model with Dynamic Constraint," Asia Marketing Journal: Vol. 18 : Iss. 4 , Article 6.

Available at: https://doi.org/10.15830/amj.2017.18.4.125

This Article is brought to you for free and open access by Asia Marketing Journal. It has been accepted for inclusion in Asia Marketing Journal by an authorized editor of Asia Marketing Journal. 


\title{
A Direct Utility Model with Dynamic Constraint
}

\author{
Byungyeon Kim* \\ Takuya Satomura** \\ Jaehwan Kim***
}

The goal of the study is to understand how consumers' constraint as opposed to utility structure gives rise to final decision when consumers purchase more than one variant of product at a time, i.e., horizontal variety seeking or multiple-discreteness. Purchase and consumption decision not only produces utility but also involves some sort of cognitive pressure. Past consumption or last purchase is likely to be linked to this burden we face such as concern for obesity, risk of harm, and guilt for mischief. In this research, the existence and the role of dynamic constraint are investigated through a microeconomic utility model with multiple dynamic constraint. The model is applied to the salty snacks data collected from field study where burden for spiciness serves as a constraint. The results are compared to the conventional multiple discreteness choice models of static constraints, and policy implications on price discounts is explored. The major findings are that first, one would underestimate the level of consumer preference for product offerings when ignoring the carry-over of the concern from the past consumption, and second, the impact of price promotion on demand would be properly evaluated when the model allows for the role of constraint as both multiple and dynamic. The current study is different from the existing studies in two ways. First, it captures the effect of 'mental constraint' on demand in formal economic model. Second, unlike the state dependence well documented in the literature, the study proposes the notion of state dependence in different way, via constraint rather than utility.

Key words: consumer choice, multiple discreteness, mental burden, Bayesian estimation

\footnotetext{
* Harvard Business School, Harvard University (bkim@hbs.edu)

** Faculty of Business and Commerce, Keio University(satomura@fbc.keio.ac.jp)

*** Korea University Business School, Korea University (jbayes@korea.ac.kr), Corresponding Author
} 


\section{Introduction}

Consumer decision-making often comes under costs or resources they must give up such as price, time, and concern. These physical or mental costs are typically bounded each by their maximum allowable levels of resources consumers have, which serve to limit their desires. Conventional studies have typically assumed this constrained nature of consumption to be independent over time. In reality, however, the amount of allocation for each of the constraints is likely to be affected by consumer's consumption history. For instance, someone who had a large dish of ribeye steak the day before is likely to look for something that is light and lean for the following lunch due to her increased concern on the calories and fat accumulated. This retrieval acts as mental or psychological burden that serves to further limit current consumption.

The stream of modeling literature on consumer choice has focused primarily on various functional forms dealing with utility structure, while paying less attention to the constraints in presence. Studies that capture the multiple discreteness in demand (Kim et al. 2002, 2007; Dube 2004; Bhat 2005, 2008) subject to a single budget (monetary expenditure) constraint are some examples. An exception to the sparse constraintfocused approach in marketing comes from Satomura et al(2011), which introduces a framework of multiple binding constraints, and applies the model to conjoint data incorporating price and quantity restrictions. However, the constraint structure in these studies can be limited in capturing aforementioned mental burden since the constraint structure is assumed to be static.

In this study, we propose a direct utility model with dynamic constraints to account for cognitive pressure arising from past consumption. Under the general framework of constrained utility maximization (Hanemann 1984), we impose structural state dependence in the constraints to link consumption history to current purchase likelihood. The structure takes the form of inventory of burdensome product characteristics, and is 'mentally' generated by temporal carryover of the inventory through physiological processing (McAlister 1982). As the inventory of mental burden grows over time, it serves to limit constant consumption of offerings that possess excess amount of those characteristics, which results in a shift in brand choice or change in resource allocation. This constraintbinding process occurs even when the focal choice offering gives greater utility gain (i.e., higher marginal utility) than other offerings. From the previous example, although one's marginal utility may still be the same for having rib-eye steak again (want to), because of the concern of gaining weight (but not able to), she instead ends up choosing a leaner choice with lower marginal utility.

Using the salty snacks data from a field study, we show that failure to take account for the 
dynamics in the constraints leads to biased estimates of consumer preference parameters and overly optimistic sales forecasts for price promotions. By accounting for the psychological burden carried over from previous consumptions, firms can infer consumer price elasticity more accurately, and thus make more precise prediction on sales upon price. The dynamic constraints model also allows for evaluation of the trade-off relationship between price and product characteristics, which is critical in the firm's product configuration perspective.

The remainder of the paper is organized as follows: In section 2 we develop the model, and formulate the likelihood. Subsequently, the model is applied to the field experiment data in section 3, where comparison is made to benchmark models. Section 4 discusses implications of our model through policy experiments, and concluding remarks are offered in section 5 .

\section{Model}

\subsection{Model Development}

The development of the model is based on the constrained utility maximization framework with the associated constraints being multiple (Satomura et al 2011) and dynamic, i.e., dependent on previous consumption decision. We begin with an arbitrary utility function $\mathrm{U}(\mathrm{x})$ :

$$
\begin{aligned}
& \text { Maximize } \mathrm{U}\left(\mathrm{x}_{\mathrm{kt}}\right) \\
& \text { Subject to } \sum_{\mathrm{n}} \mathrm{p}_{\mathrm{knt}} \mathrm{x}_{\mathrm{knt}}+\mathrm{x}_{\mathrm{kzt}}=\mathrm{M}_{\mathrm{k}} \\
& \sum_{\mathrm{n}} \mathrm{w}_{\mathrm{kcnt}} \mathrm{x}_{\mathrm{knt}}+\eta_{\mathrm{kct}}+\mathrm{x}_{\mathrm{kcwt}}=\mathrm{W}_{\mathrm{kc}}
\end{aligned}
$$

where

$$
\begin{aligned}
& \eta_{\mathrm{kct}}=\sum_{\mathrm{p}=1}^{\mathrm{t}-1}\left(\delta_{\mathrm{kc}}^{\mathrm{t}-\mathrm{p}} \cdot \sum_{\mathrm{n}} \mathrm{w}_{\mathrm{kcnp}} \mathrm{x}_{\mathrm{knp}}\right), \eta_{\mathrm{kc} 0}=0 \\
& \mathrm{k}: \text { individual }(\mathrm{k}=1, \cdots, \mathrm{K}) \\
& \mathrm{n}: \text { offering }(\mathrm{n}=1, \cdots, \mathrm{N}) \\
& \mathrm{t}: \text { occasion } \\
& \mathrm{c}: \mathrm{c}^{\text {th }} \text { constraint }(\mathrm{c}=1, \cdots, \mathrm{C}) \\
& \mathrm{p}_{\mathrm{knt}}: \text { price of offering } n \text { at } t \text { for individual } k \\
& \mathrm{~W}_{\mathrm{kcnt}}: \text { amount of burden } c \text { carried by offering } n \text { at } t \\
& \eta_{\mathrm{kct}}: \text { inventory of burden } c \text { cumulated before } t \\
& \delta_{\mathrm{kc}}: \text { rate of depreciation of burden } c \text { for individual } \\
& \quad k(0<\delta<1) \\
& \mathrm{M}_{\mathrm{k}}: \text { maximum monetary budget } \\
& \mathrm{W}_{\mathrm{kc}}: \text { maximum level that tolerate the burden } \mathrm{c}
\end{aligned}
$$

An individual $k$ maximizes her utility at choice occasion $t$, subject to given constraints. The first constraint in (1) is the conventional budget constraint. The main difference with Satomura et al (2011) occurs over the subsequent constraints $(c=1,2, \cdots, C)$, which are constituted by both $\mathrm{w}_{\mathrm{n}}$, marginal concern (or burden) that one has to allow for each quantity demanded $\mathrm{x}_{\mathrm{n}}$, and $n_{\mathrm{kct}}$, the inventory of burden accumulated to time $t$. This inventory $n_{c t}$ incorporates temporal dynamics, and is built up by the sum of one's concerns consumed in the past. We employ an exponential decay for the depletion 
of burdens over each occasion by the retention ratio $\delta_{\text {kc. }}$. The inventory at the beginning $(t=0)$ is assumed to be zero $\left(n_{k c 0}=0\right)$. Since constraints are constructed at the product characteristics level, the dynamics are captured through the product characteristics space across all offerings (i.e., overall consumption of the characteristics induce temporal dependence).

For each constraint, we introduce outside goods $\mathrm{x}_{\mathrm{z}}$ and $\mathrm{x}_{\mathrm{cW}}(\mathrm{c}=1,2, \cdots, \mathrm{C})$. These outside goods are assumed to have strictly positive demand. Thus, we assume that the quantity demanded within the product category does not completely exhaust its constraint allotments for each of the consecutive constraints. Note that the inventory of burden, $n_{k c t}$, also limits one's consumption at occasion $t$ (i.e., $\left.\mathrm{W}_{\mathrm{kc}}-\eta_{\mathrm{kcc}}\right)$.

\subsection{Likelihood and Heterogeneity}

We employ a variant of the direct utility model framework proposed by Kim et al (2002). This utility specification for multiple choice offerings allows for both corner and interior solutions, which makes possible to observe the quantity allocation changes occurring under the dynamics of the constraint structure.

$$
\begin{aligned}
\mathrm{U}\left(\mathrm{x}_{\mathrm{kt}}\right)= & \sum_{\mathrm{n}}^{\mathrm{N}} \psi_{\mathrm{knt}} \ln \left(\mathrm{x}_{\mathrm{knt}}+1\right)+\psi_{\mathrm{kz}} \ln \left(\mathrm{x}_{\mathrm{kzt}}\right) \\
& +\sum_{\mathrm{c}=1}^{\mathrm{C}} \psi_{\mathrm{kcw}} \ln \left(\mathrm{x}_{\mathrm{kcwt}}\right)
\end{aligned}
$$

The stochastic specification is obtained by introducing the error term in the baseline marginal utility $\left(\Psi_{\mathrm{knt}}=\exp \left(\psi_{\mathrm{kn}}+\varepsilon_{\mathrm{knt}}\right)\right)$. We assume that $\varepsilon_{\text {knt }}$ follows the Type I extreme value distribution. The utility parameters associated with outside goods are restricted for statistical identification, i.e., $\psi_{\mathrm{kz}}=1$ and $\psi_{\mathrm{kcw}}=1$.

The Kuhn-Tucker (KT) conditions associated with the first-order conditions of the observed demand are given by:

$$
\begin{gathered}
\frac{\psi_{\mathrm{knt}}}{\mathrm{x}_{\mathrm{knt}}+1}=\frac{\mathrm{p}_{\mathrm{knt}} \psi_{\mathrm{kz}}}{\mathrm{x}_{\mathrm{kzt}}}+\sum_{\mathrm{c}=1}^{\mathrm{c}} \frac{\mathrm{w}_{\mathrm{kcnt}} \psi_{\mathrm{kcw}}}{\mathrm{x}_{\mathrm{kcwt}}} \\
\quad \text { if } \mathrm{x}_{\mathrm{knt}}>0 \\
\frac{\psi_{\mathrm{knt}}}{\mathrm{x}_{\mathrm{knt}}+1}<\frac{\mathrm{p}_{\mathrm{knt}} \psi_{\mathrm{kz}}}{\mathrm{x}_{\mathrm{kzt}}}+\sum_{\mathrm{c}=1}^{\mathrm{c}} \frac{\mathrm{w}_{\mathrm{knnt}} \psi_{\mathrm{kcw}}}{\mathrm{x}_{\mathrm{kcwt}}} \\
\text { if } \mathrm{x}_{\mathrm{knt}}=0
\end{gathered}
$$

By taking logarithm of (5) and (6), and rearranging the terms, we have:

$$
\begin{array}{ll}
\varepsilon_{k n t}=\mathrm{g}_{\mathrm{knt}} & \text { if } \mathrm{X}_{\mathrm{knt}}>0 \\
\varepsilon_{k n t}<\mathrm{g}_{\mathrm{knt}} & \text { if } \mathrm{X}_{\mathrm{knt}}=0
\end{array}
$$

where

$$
\begin{aligned}
& \mathrm{g}_{\mathrm{knt}}=-\psi_{\mathrm{kn}}+\ln \left(\mathrm{x}_{\mathrm{knt}}+1\right)+ \\
& \ln \left(\frac{\mathrm{p}_{\mathrm{knt}} \psi_{\mathrm{kz}}}{\mathrm{M}_{\mathrm{k}}-\sum_{\mathrm{n}} \mathrm{p}_{\mathrm{knt}} \mathrm{x}_{\mathrm{knt}}}+\sum_{\mathrm{c}=1}^{\mathrm{C}} \frac{\mathrm{w}_{\mathrm{knn}} \psi_{\mathrm{kcw}}}{\mathrm{W}_{\mathrm{kc}}-\sum_{\mathrm{n}} \mathrm{w}_{\mathrm{knnt}} \mathrm{x}_{\mathrm{knt}}-\eta_{\mathrm{kct}}}\right)
\end{aligned}
$$

As $n_{k c t}$ increases in the last term, the corre- 
sponding constraint $\left(\mathrm{W}_{\mathrm{kc}}\right)$ that allows individual $k$ to tolerate the burden $c$ decreases to the same extent, and thus, the effect of the same amount of marginal concern $\mathrm{W}_{\mathrm{kcn}}$ in the numerator on $g_{k n t}$ becomes amplified. This state dependence occurs through constraint as opposed to utility changes, which was not captured in the literature.

Based on the first order conditions above, the likelihood for the observed $\operatorname{data}\left(\mathrm{x}^{*}\right)$ that total $\mathrm{R}$ out of $\mathrm{N}$ offerings are purchased is given by:

$$
\begin{aligned}
& \mathrm{P}\left(\mathrm{x}_{\mathrm{k}, \mathrm{n} 1, \mathrm{t}}^{*}>0 \text { and } \mathrm{x}_{\mathrm{k}, \mathrm{n} 2, \mathrm{t}}^{*}=0 \text { for } \mathrm{n} 1=1, \ldots, \mathrm{R}\right. \\
& \text { and } \mathrm{n} 2=\mathrm{R}+1, . ., \mathrm{N}) \\
& =\left|\mathrm{J}_{\mathrm{kt}}\right| \cdot \int_{-\infty}^{\mathrm{g}_{\mathrm{k}, \mathrm{N}, \mathrm{t}}} \cdots \int_{-\infty}^{\mathrm{g}_{\mathrm{k}, \mathrm{R}+1, \mathrm{t}}} \mathrm{f}\left(\mathrm{g}_{\mathrm{k}, 1, \mathrm{t}}, \ldots, \mathrm{g}_{\mathrm{k}, \mathrm{R}, \mathrm{t}}, \varepsilon_{k, R+1, t}, \ldots, \varepsilon_{k, N, t}\right) \\
& \mathrm{d} \varepsilon_{\mathrm{k}, \mathrm{R}+1, \mathrm{t}} \cdots \mathrm{d} \varepsilon_{\mathrm{k}, \mathrm{N}, \mathrm{t}}
\end{aligned}
$$

where $f(\cdot)$ is the joint density distribution for the error terms $(\varepsilon)$ assumed to be distributed $\mathrm{N}(0, \mathrm{I})$ and $\left|\mathrm{J}_{\mathrm{kt}}\right|$ is the Jacobian based on $(\mathrm{R} \times \mathrm{R})$ mapping from random-utility error $(\varepsilon)$ to the likelihood of the observed data $\left(x^{*}\right)$. In this model, the Jacobian is given by:

$$
\begin{aligned}
& \mathrm{J}_{\mathrm{kt}(\mathrm{i}, \mathrm{j})}=\frac{\mathrm{I}_{\mathrm{i}=\mathrm{j}}}{\mathrm{x}_{\mathrm{knt}}+1}+ \\
& \frac{\left[\left(\mathrm{p}_{\mathrm{kit}} \mathrm{p}_{\mathrm{kjt}}\right) / \mathrm{x}_{\mathrm{kzt}}^{2}\right]+\left[\sum_{\mathrm{c}=1}^{\mathrm{C}}\left(\mathrm{w}_{\mathrm{kcit}} \mathrm{w}_{\mathrm{kcjt}}\right) / \mathrm{x}_{\mathrm{kcwt}}^{2}\right]}{\left[\left(\mathrm{p}_{\mathrm{kit}}\right) / \mathrm{x}_{\mathrm{kzt}}\right]+\left[\sum_{\mathrm{c}=1}^{\mathrm{C}}\left(\mathrm{w}_{\mathrm{kcit}} / \mathrm{x}_{\mathrm{kcwt}}\right)\right]}
\end{aligned}
$$

where $I_{i=j}=1$ if $\mathrm{i}=\mathrm{j}$ and 0 otherwise.
Finally, the model parameters in the likelihood are specified at individual consumer level. Consumer heterogeneity is specified by a multivariate normal distribution:

$$
\theta_{\mathrm{k}} \equiv\left(\psi_{\mathrm{k}}, \mathrm{M}_{\mathrm{k}}^{*}, \mathrm{~W}_{\mathrm{kc}}^{*}, \delta_{\mathrm{kc}}^{*}\right)^{\prime} \sim \mathrm{N}\left(\bar{\theta}, \mathrm{V}_{\theta}\right)
$$

where $\quad \mathrm{M}_{\mathrm{k}}^{*}=\ln \left(\mathrm{M}_{\mathrm{k}}\right), \quad \mathrm{W}_{\mathrm{kc}}^{*}=\ln \left(\mathrm{W}_{\mathrm{kc}}\right), \quad$ and $\delta_{\mathrm{kc}}^{*}=\ln \left(\frac{\delta_{\mathrm{kc}}}{1-\delta_{\mathrm{kc}}}\right)^{\prime}$ to guarantee $\mathrm{M}_{\mathrm{k}}>0, \mathrm{~W}_{\mathrm{kc}}>0$, and $0<\delta_{\mathrm{kc}}<1$.

\section{Empirical Analysis}

\subsection{Data Description}

The data used for the empirical study are from a field experiment on purchase of salty snacks conducted in the United States that were also used in Kim et al (2007). Respondents were given a weekly budget of $\$ 2.00$ to choose among 8 varieties of corn chips (i.e., $M_{k}=2.00$ ). Each offering was priced at $\$ 0.33$, whereas the regular price of these chips was $\$ 0.99$. The offering of chips at reduced prices induced higher levels of consumption, which could provide closer information over the effect of product characteristics and their temporal accumulation of mental burden. In total, 101 university students participated in the experiment, and were allowed 
to visit on a fixed day (Wednesday) for 7 weeks. For each visit, students were instructed to purchase the chips for their own consumption, and their remaining budgets were paid in cash at the end of the experiment. Because the student panel experienced a fair amount of attrition towards the end of the study, the total number of data points collected was 634 . We retain the last observation for each respondent as holdout sample. The rest of the observations are used to calibrate the model and to report the insample model fit in the subsequent analyses. Summary statistics reported in Table 1 reveal that the vast majority of choice occasions exhibited multiple-discreteness.

The manufacturer provided detailed charac- teristics of the product, and one of the characteristics was selected as a form of the dynamic constraint $(c=1)$. This characteristic, which is disguised for proprietary purposes, reflects the taste of the product in the form of how "hot" or "spicy" the snack is. The associated characteristics $\left(\mathrm{w}_{\mathrm{n}}\right)$ for each of the choice offerings are shown on Table 2.

\subsection{Model Fit}

Joint posterior distribution of parameters was estimated via MCMC in the Hierarchical Bayesian framework. In addition to the proposed model, two alternative models for multiple-discreteness data were also fit as benchmark. Difference

$\langle$ Table 1〉 Data Summary

\begin{tabular}{ccccc}
\hline \multirow{2}{*}{ Flavor* } & \multicolumn{3}{c}{ Purchase Incidence } & \multirow{2}{*}{ Purchase Quantity } \\
\cline { 2 - 4 } & Total Purchase & Corner Solution & Interior Solution & 224 \\
2 & 168 & - & $168(1.00)$ & 262 \\
3 & 177 & $4(0.02)$ & $173(0.98)$ & 231 \\
4 & 188 & - & $188(1.00)$ & 235 \\
5 & 180 & - & $180(1.00)$ & 295 \\
6 & 190 & $2(0.01)$ & $188(0.99)$ & 446 \\
7 & 244 & $6(0.02)$ & $238(0.98)$ & 338 \\
8 & 235 & - & $235(1.00)$ & 277 \\
\hline Total & 218 & - & $218(1.00)$ & 2308 \\
\hline
\end{tabular}

* 1: Nacho cheesier 3D, 2: Spicier nacho, 3: Cooler ranch 3D, 4: Baja picante

5: Jalapeno cheddar 3D, 6: Nacho cheesier, 7: Cooler ranch, 8: Sonic sour cream

〈Table 2〉 Characteristic Content for Offerings

\begin{tabular}{r|cccccccc}
\hline Flavor $(n)$ & 1 & 2 & 3 & 4 & 5 & 6 & 7 & 8 \\
\hline Amounts $\left(W_{n}\right)$ & .20 & .425 & .40 & .55 & .50 & .20 & .40 & .00 \\
\hline
\end{tabular}


among the models are in the specification on constraint and there is no difference in utility structure used. First benchmark model(BM1) is a baseline one where only budget constraint enters utility maximization (i.e., single-constraint model).

$$
\begin{array}{ll}
\text { Maximize } & \mathrm{U}\left(\mathrm{x}_{\mathrm{kt}}\right) \\
\text { Subject to } & \sum_{\mathrm{n}} \mathrm{p}_{\mathrm{knt}} \mathrm{x}_{\mathrm{knt}}+\mathrm{x}_{\mathrm{kzt}}=\mathrm{M}_{\mathrm{k}}
\end{array}
$$

Second benchmark model(BM2) allows for adding a second constraint for spiciness, which results in the multiple constraints (Satomura et al. 2011), yet no dynamic dependence $(n=0)$.

$$
\begin{array}{ll}
\text { Maximize } & \mathrm{U}\left(\mathrm{x}_{\mathrm{kt}}\right) \\
\text { Subject to } & \sum_{\mathrm{n}} \mathrm{p}_{\mathrm{knt}} \mathrm{x}_{\mathrm{knt}}+\mathrm{x}_{\mathrm{kzt}}=\mathrm{M}_{\mathrm{k}} \\
& \sum_{\mathrm{n}} \mathrm{w}_{\mathrm{kcnt}} \mathrm{x}_{\mathrm{knt}}+\mathrm{x}_{\mathrm{kcwt}}=\mathrm{W}_{\mathrm{kc}}
\end{array}
$$

The model fits are reported in Table 3 . The proposed model outperforms the benchmark models in two measures of fit - log-marginal density
(Newton and Raftery 1994) and the Bayesian deviance information criterion (Spiegelhalter et al. 2002). Predictive fit, the mean squared distance, shows that the three models are in close proximity. In the next section, we discuss how these differences in model fits are translated to bias in the parameter estimates.

\subsection{Parameter Estimates}

The parameter estimates are in Table 4 and were obtained based on last 10,000 draws from 100,000 iterations. Although, budget is specified as one of the parameters $\left(M_{k}\right)$, we fix $M_{k}=2$ since the weekly budget was exogenously given to every respondent.

First of all, it is obvious that ignoring the existence of burden carried over from the past consumption results in a systematic downward bias in preference parameters. This finding indicates that consumer's preference for product offering does not change due to the past consumption, but due to a relative reduction in her ability or capacity to consume the product, which

〈Table 3〉 Model fit comparison

\begin{tabular}{lcccccc}
\hline \multirow{2}{*}{ Model } & \multicolumn{2}{c}{ Description } & \multirow{2}{*}{ LMD $^{\mathrm{a}}$} & \multirow{2}{*}{ DIC $^{\mathrm{b}}$} & \multirow{2}{*}{ MSD $^{\mathrm{c}}$} \\
\cline { 2 - 3 } & Constraint & Dynamic & & & \\
\hline BM 1 & Single & No & & -4929.6 & 10167.3 & .6724 \\
BM 2 & Multiple & No & & -4550.9 & 9300.8 & .6648 \\
Proposed & Multiple & Yes & -4316.7 & 8701.5 & .6639 \\
\hline
\end{tabular}

\footnotetext{
${ }^{a}$ Log marginal density

${ }^{\mathrm{b}}$ Deviance information criterion

${ }^{c}$ Mean squared distance
} 
〈Table 4〉 Posterior distribution of parameters: Mean

(Standard deviation)

\begin{tabular}{c|cccccccc|cc}
\hline Parameter & $\bar{\psi}_{1}$ & $\bar{\psi}_{2}$ & $\bar{\psi}_{3}$ & $\bar{\psi}_{4}$ & $\bar{\psi}_{5}$ & $\bar{\psi}_{6}$ & $\bar{\psi}_{7}$ & $\bar{\psi}_{8}$ & $\overline{\mathrm{W}}^{*}$ & $\bar{\delta}^{\star}$ \\
\hline \multirow{2}{*}{ BM 1 } & -2.07 & -2.00 & -1.83 & -1.93 & -1.87 & -1.65 & -1.58 & -1.61 & & \\
& $(0.26)$ & $(0.28)$ & $(0.24)$ & $(0.26)$ & $(0.25)$ & $(0.28)$ & $(0.26)$ & $(0.24)$ & - & - \\
\multirow{3}{*}{ BM 2 } & -1.58 & -1.36 & -1.14 & -1.16 & -1.16 & -1.31 & -0.86 & -1.63 & 1.07 & - \\
& $(0.24)$ & $(0.26)$ & $(0.22)$ & $(0.24)$ & $(0.21)$ & $(0.33)$ & $(0.25)$ & $(0.22)$ & $(0.12)$ & \\
\multirow{2}{*}{ Proposed } & -1.30 & -1.04 & -0.98 & -0.96 & -0.91 & -1.10 & -0.76 & -1.66 & 1.23 & -1.21 \\
& $(.25)$ & $(.25)$ & $(.23)$ & $(.22)$ & $(.21)$ & $(.32)$ & $(.25)$ & $(.23)$ & $(.13)$ & $(.49)$ \\
\hline
\end{tabular}

eventually limits the observed purchase.

The baseline marginal utility in the proposed model is the highest for offering 7 with mean value of -0.76 , and the lowest for offering 8 with -1.66. For dynamic constraint parameters, the estimated mean value of maximum capacity for spiciness $\left(\bar{W}^{*}\right)$ is 1.23 and retention ratio $\left(\bar{\delta}^{*}\right)$ is -1.21 . Converting $\delta^{*}$ estimates back to its original interval $(0,1)$ for $\delta$ yields 0.24 (0.09) as mean, which implies that consumers accumulate their burden of having too much of spiciness by $24 \%$ on average. The gap in maximum capacity parameters $\left(\bar{W}^{*}\right)$ between the proposed and multiple constraints models(BM2) reflects the existence of mental burden that is carried over in other ways. The estimation of these individual level retention ratio and constraint allotment would allow for the segmentation of consumers with respect to their responses upon presence of burden-generating product characteristics.

We investigate the unobserved heterogeneity in the parameter estimates for the proposed model, which shows the best model fit to data. The entire heterogeneity variance-covariance $\operatorname{matrix}\left(V_{\Theta}\right)$ in (12) is provided in Table 5. The correlations (upper triangle) for the baseline marginal utility parameters are found to be uniformly positive in the $(0.37,0.81)$ range. Heterogeneity for marginal utility parameter for offering 6 is high relative to other varieties, in part due to a few loyal consumers who purchased only that offering during the entire experiment. On the other hand, preference for offering 5 is found to be least heterogeneous across respondents. Regarding the dynamic constraint parameters, maximum capacity for spiciness is negatively (positively) correlated with offerings that possess less (more) of the characteristic with the exception for offering 8 . Retention ratio parameter shows uniformly negative correlations with baseline marginal utility parameters, and are especially strong for offerings with less amount of spiciness. 
〈Table 5〉 Variance-Covariance (Correlation) Matrix

\begin{tabular}{c|cccccccccc}
\hline Parameter & $\Psi_{1}$ & $\Psi_{2}$ & $\Psi_{3}$ & $\Psi_{4}$ & $\Psi_{5}$ & $\Psi_{6}$ & $\Psi_{7}$ & $\Psi_{8}$ & $\mathrm{~W}^{*}$ & $\delta^{*}$ \\
\hline \multirow{4}{*}{$\Psi_{1}$} & 4.76 & .67 & .79 & .55 & .72 & .68 & .44 & .47 & -.14 & -.35 \\
& $(0.88)$ & & & & & & & & & \\
& 3.11 & 4.53 & .58 & .81 & .66 & .56 & .60 & .71 & .24 & -.12 \\
& $(0.65)$ & $(0.77)$ & & & & & & & & \\
\multirow{4}{*}{$\Psi_{3}$} & 3.54 & 2.53 & 4.23 & .56 & .69 & .48 & .58 & .43 & -.08 & -.14 \\
& $(0.70)$ & $(0.58)$ & $(0.78)$ & & & & & & & \\
\multirow{4}{*}{$\Psi_{4}$} & 2.39 & 3.41 & 2.29 & 3.90 & .61 & .49 & .68 & .74 & .27 & -.13 \\
& $(0.57)$ & $(0.60)$ & $(0.54)$ & $(0.65)$ & & & & & & \\
& 2.80 & 2.50 & 2.51 & 2.13 & 3.17 & .37 & .34 & .58 & .15 & -.23 \\
& $(0.60)$ & $(0.53)$ & $(0.55)$ & $(0.50)$ & $(0.60)$ & & & & & \\
& 4.56 & 3.67 & 3.05 & 2.97 & 2.04 & 9.54 & .56 & .41 & -.33 & -.51 \\
& $(0.95)$ & $(0.83)$ & $(0.78)$ & $(0.73)$ & $(0.67)$ & $(1.60)$ & & & & \\
$\Psi_{7}$ & 2.12 & 2.82 & 2.65 & 2.99 & 1.33 & 3.80 & 4.92 & .58 & .07 & -.07 \\
& $(0.61)$ & $(0.62)$ & $(0.64)$ & $(0.60)$ & $(0.49)$ & $(0.87)$ & $(0.90)$ & & & \\
\multirow{4}{*}{$\Psi_{8}$} & 2.07 & 3.06 & 1.80 & 2.97 & 2.09 & 2.56 & 2.61 & 4.09 & .28 & -.30 \\
& $(0.60)$ & $(0.61)$ & $(0.53)$ & $(0.59)$ & $(0.51)$ & $(0.77)$ & $(0.59)$ & $(0.71)$ & & \\
$W^{*}$ & -0.31 & 0.50 & -0.15 & 0.52 & 0.25 & -1.00 & 0.16 & 0.56 & 0.98 & .41 \\
& $(0.28)$ & $(0.28)$ & $(0.26)$ & $(0.25)$ & $(0.22)$ & $(0.43)$ & $(0.28)$ & $(0.26)$ & $(0.21)$ & \\
$\delta^{*}$ & -2.55 & -0.87 & -1.00 & -0.86 & -1.40 & -5.28 & -0.49 & -2.02 & 1.39 & 11.29 \\
& $(1.04)$ & $(1.11)$ & $(0.96)$ & $(1.07)$ & $(0.86)$ & $(1.75)$ & $(1.19)$ & $(1.03)$ & $(0.50)$ & $(2.35)$ \\
\hline
\end{tabular}

\section{Policy Implications}

In this section, we conduct policy experiments regarding the relationship between price and spiciness, the burdensome product characteristic. Firms often encounter the decision-making problem of setting the optimal level of product characteristics and prices. In one sense, adjusting the level of product characteristics involves modifications in production process, whereas price changes can be implemented easily. On the other hand, lowering prices may harm brand equity, whereas modifying the product charac- teristics may not. A utility-based model allows us to analyze counterfactuals regarding the desirable product configurations and pricing. Based on the experimental results, firms can evaluate the outcome of characteristic changes in their products and compare the trade-off between long-term characteristics modification and shortterm pricing decisions in terms of its impact on consumer welfare or firms' profit.

To explore the effects of modifying product characteristics and prices, we use the indirect utility and numerically evaluate the maximum level of utility for any decision input. Let us define the indirect utility function $\left(\mathrm{V}_{\mathrm{kt}}\left(\mathrm{p}_{\mathrm{kt}}, \mathrm{w}_{\mathrm{kct}}\right)\right)$ 
for each observation:

$$
\begin{aligned}
& \left(\mathrm{V}_{\mathrm{kt}}\left(\mathrm{p}_{\mathrm{kt}}, \mathrm{W}_{\mathrm{kct}}\right)\right)=\max _{x} \mathrm{U}\left(\mathrm{x}_{\mathrm{kt}} \mid \psi_{\mathrm{k}}\right) \\
& \text { subject to } \mathrm{p}_{\mathrm{kt}}^{\prime} \mathrm{x}_{\mathrm{kt}}+\mathrm{x}_{\mathrm{kzt}}=\mathrm{M}_{\mathrm{k}} \\
& \mathrm{W}_{\mathrm{kct}}^{\prime} \mathrm{x}_{\mathrm{kt}}+\sum_{p=1}^{t-1}\left(\left(\delta_{k c}\right)^{t-\rho} \cdot \mathrm{W}_{\mathrm{kcp}}^{\prime} \mathrm{x}_{\mathrm{kp}}\right)+\mathrm{x}_{\mathrm{kcwt}}=\mathrm{W}_{\mathrm{kc}}
\end{aligned}
$$

Note that our empirical analysis was subject to one dynamic constraint $(c=1)$, and the values of $M_{k}$ were fixed at $\$ 2.00$. Thus, conditional on individual level estimates of $\left(\psi_{\mathrm{k}}^{\prime}, \mathrm{W}_{\mathrm{k}}^{*}, \delta_{\mathrm{k}}^{*}\right)^{\prime}$ obtained from the model, we perform two types of calculations: (1) to compute the adjustment in product characteristic equivalent to price reduction that results in the same level of aggregate indirect utility, and (2) to compare the differential effects of price reduction on demand across different model specifications.

\subsection{Adjusting Product Characteristics}

We present the utility-equivalent relationship between product characteristic adjustment and price reduction. We do so by calculating the price discount $\left(\mathrm{d}^{*}\right)$ that is equivalent in overall utility level to the given reduction in burden generating product characteristic $\left(\mathrm{r}^{*}\right)$. The results are obtained by solving the following problem:

$$
\text { find } d^{*} \mid r^{0} \text { such that } \bar{V}\left(r^{0}\right)=\bar{V}\left(d^{*}\right) \text { and }
$$

find $r^{*} \mid d^{0}$ such that $\bar{V}\left(r^{*}\right)=\bar{V}\left(d^{0}\right)$

where

$$
\begin{aligned}
& \overline{\mathrm{V}}\left(\mathrm{r}^{*}\right)=\sum_{k=1}^{\mathrm{K}} \sum_{t=1}^{\mathrm{T}} \mathrm{V}_{\mathrm{kt}}\left(\mathrm{p}_{\mathrm{kt}},\left(1-\mathrm{r}^{*}\right) \cdot \mathrm{W}_{\mathrm{kct}}\right) \\
& \overline{\mathrm{V}}\left(\mathrm{d}^{*}\right)=\sum_{k=1}^{\mathrm{K}} \sum_{t=1}^{\mathrm{T}} \mathrm{V}_{\mathrm{kt}}\left(\left(1-\mathrm{d}^{*}\right) \cdot \mathrm{p}_{\mathrm{kt}}, \mathrm{W}_{\mathrm{kct}}\right)
\end{aligned}
$$

Note that the modification occurs by the same percentage amount for the whole vector of either $\mathrm{w}_{\mathrm{kct}}$, product characteristics (holding fixed price), or $\mathrm{p}_{\mathrm{k} t}$, prices (holding fixed level of characteristic). Table 6 presents the utility-equivalent price discounts to each of the adjustments in product characteristics.

〈Table 6〉 Utility-Equivalent Adjustments in Characteristic-Price

\begin{tabular}{cc}
\hline $\begin{array}{c}\text { Reduction in } \\
\text { characteristic }\left(\mathrm{r}^{*}\right)\end{array}$ & $\begin{array}{c}\text { Price discount } \\
\left(\mathrm{d}^{*}\right)\end{array}$ \\
\hline $1 \%$ & $14.35 \%$ \\
$2 \%$ & $26.48 \%$ \\
$3 \%$ & $37.48 \%$ \\
$5 \%$ & $52.41 \%$ \\
$10 \%$ & $83.02 \%$ \\
\hline
\end{tabular}

The results show that the effect of changes in product configuration with a small reduction in burdensome characteristic on utility gains is much greater than its price discount equivalent. While this may seem inflated and unintuitive at the first glance, note that the prices for the chips were offered under hefty price discounts to induce consumption, and thus the utility 
sensitivity to price was kept low. For example, $2 \%$ reduction in burdensome characteristics would bring an increase in sales that would have needed 26.48\% discount if marker were to choose price discount to stimulate the demand. The results indicate that in the long run, firms now can achieve sales increase without going through price discount at the expense of harming brand.

\subsection{Pricing Implications}

In order to explore managerial implication of modeling dynamic constraint in predicting $\mathrm{de}^{-}$ mand, we examine pricing implication as the second policy experiment. We investigate the shift in demand due to price reduction and compare the differences across models. Figure 1 shows the demand side impact of price re- duction when the entire vector of prices is reduced by 20\%.' The values were obtained as percentage increase in demand upon the null condition (no discount, d. $=0$ ).

As Wertenbroch (1998) noted, demand for products with negative characteristics increases less in response to price reductions due to consumers' self-imposed constraints. The results in figure 1 demonstrate the phenomenon. Offering 8, with no content for spiciness, absorbs a high portion of the increase in demand from price discounts. On the other hand, offerings 3 and 7 show the least favorable of discounts due to their spice contents. While this result may seem peculiar in that offerings 2,4 , and 5 contain more of the spiciness, the underlying $\mathrm{ra}^{-}$ tionale can be found tracing back to the heterogeneity matrix $\left(V_{\ominus}\right)$. Baseline utility parameters for offerings 3 and 7 are less in correlation

〈Figure 1〉 Impact of Price Reduction $\left(d^{*}=20 \%\right)$

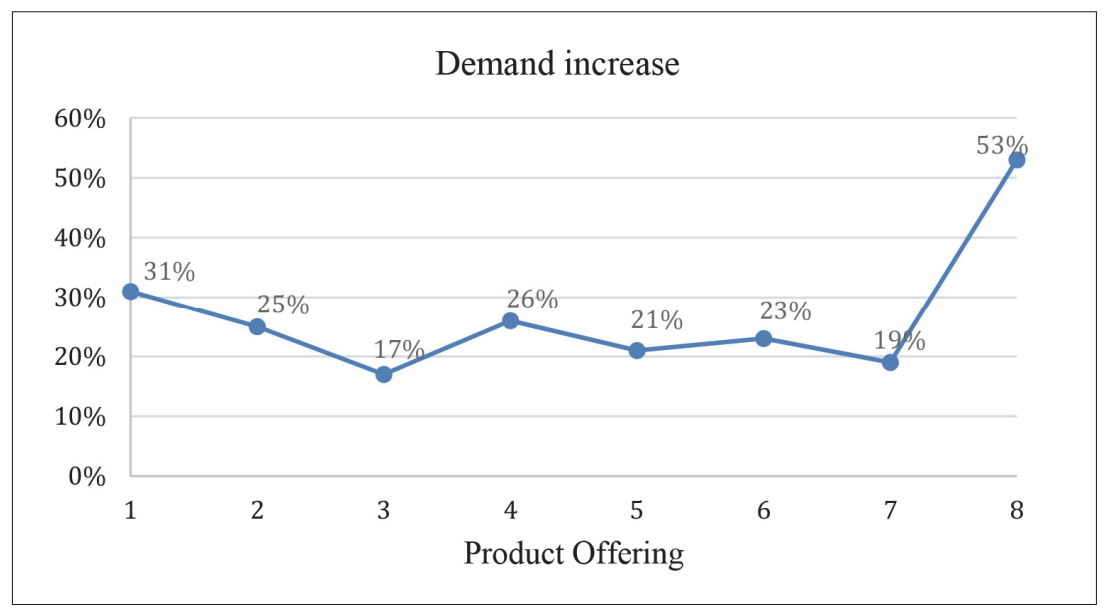

1) Results from other percentage settings are analogous and are available from the authors upon request. 
with the capacity parameter $\left(\operatorname{corr}\left(\Psi_{3}, W_{\mathrm{k}}{ }^{*}\right)=\right.$ $\left.-.076, \operatorname{corr}\left(\Psi_{7}, W_{\mathrm{k}}{ }^{*}\right)=.073\right)$ whereas for offerings 2, 4, and 5 they are positively correlated (i.e., .24, .27, .15). In other words, respondents with higher preference for offerings 2, 4, and 5 are yet more tolerant of spice and thus are less governed by the constraint.

\section{Concluding Remarks}

The dependence of the current choice decision on the past consumption is a reality rather than a hypothesis. Whether the changes in consumers' current choice decision as a result of such temporal dependence occur via changes in marginal utility (i.e., they like more or they come to dislike) or changes in constraints (i.e., they still like it but cannot consume) is an empirical question. In literature, many studies dealing with state-dependence (e.g., Gupta et al. 1997; Seetharaman 2003, 2004) follow the former view and allow marginal utility to be dependent on past choice. The current study attempts to propose a modeling framework to capture the state dependence that occurs over constraint as opposed to utility.

In this research, we propose an economic utility model accounting for cognitive pressure arising from past consumption to capture the dynamics in consumer's allocation decision across multiple varieties. The model nests the multiple constraints model (e.g., Satomura et al., 2011) as a special case where $\delta \rightarrow 0$, and the standard direct utility model with budget constraint only (e.g., Kim et al. 2002, 2007; Bhat 2005, 2008) when the dynamic constraints are not binding. The model was estimated against a field $\mathrm{ex}^{-}$ periment data on salty snacks, and outperformed the conventional models of static constraints. Based on the estimates of the model parameters, we explore policy implications for pricing by undertaking utility-based calculations. The findings reveal that firms can be better off by adjusting burdensome characteristics of products rather than price change because the existence of mental burden limits the probable outcome of price discounts.

Suppose that there exists a characteristic inside a product that brings high level of cognitive pressure. When a consumer consumes this product, cognitive pressure builds up as time passes by, eventually resulting in a shift in demand for other products even if her marginal utility for the original product remains the same. Conventional models that either do not incorporate dynamics in the constraint or allow for temporal dependence only through preference would regard this decrease in purchase as the product offering simply being less preferred. These under-specified models result in the estimates that drive marketing managers to overstate the product's price elasticity.

Upon the same condition, the existence of dynamic constraints in the model can reveal 
that although the consumer wants to consume these offerings, she could not consume any more due to accumulated concern. This information enables firms to understand the limitations underlying their decision based solely on price, and find out the need for adjusting the product characteristics that carry cognitive pressure. Moreover, by identifying the heterogeneity in consumer response to the burdensome characteristics, firms can engage in different marketing actions for different market sectors, such as placing advertisements that relieve the temporal carryover of pressure for those who are conscious about their past consumptions.

A limiting aspect of our research would be the use of salty snacks field experiment data. We acknowledge that our data on spiciness might seem a slight stretch to be looked as 'consumption vice'. However, the data and the model fit show that consumers are indeed affected by the mental burden on spiciness and are conscious of the previous spice consumption levels when making their purchase decision. Also, modifying product characteristics in our policy experiment is not easy in the field relative to product adjustment. Manufacturer of salty snack data used in the current stud would implement product configuration relatively easily. It would be desirable to apply the proposed model to other data that are potentially very informative about mentally constrained behavior, for instance, alcohol proof on liquor consumption, drug prescription, and calorie consumption. In addition, adding hierarchical structure that connects constraints to consumer characteristics will be certainly an interesting avenue for future research. 〈Received February 3. 2017〉 〈Revised February 3. 2017〉 〈Accepted February 10. 2017〉

\section{References}

Bhat, C. R. (2005), “A multiple discrete-continuous extreme value model: Formulation and application to discretionary time-use decisions," Transportation Research, 39 (8), 679-707.

(2008), "The multiple discrete-continuous extreme value (mdcev) model: Role of utility function parameters, identification considerations, and model extensions," Transportation Research, 42 (3), 274-303.

Dube, Jean-Pierre (2004), "Multiple discreteness and product differentiation: Demand for carbonated soft drinks," Marketing Science, 23 (1), 66-81.

Gupta, Sachin, Pradeep K. Chintagunta, and Dick R. Wittink (1997), “Accommodating Heterogeneity and State Dependence in a Model of Purchase Strings: Empirical Analysis and Managerial Implications," International Journal of Research in Marketing, 14 (4), 189-213.

Hanemann, W. Michael (1984), “Discrete/continuous 
models of consumer demand," Econometrica, 52, 541-561.

Kim, Jaehwan, Greg M. Allenby, and Peter E. Rossi (2002), "Modeling consumer demand for variety," Marketing Science, 21 (3), 229-250.

(2007), "Product attributes and models of multiple discreteness," Journal of Econometrics, 138 (1), 208-230.

McAlister, Leigh (1982), "A dynamic attribute satiation model of variety-seeking behavior," Journal of Consumer Research, 141-150.

Newton, M. A. and A. E. Raftery (1994), Approximating Bayesian inference with the weighted likelihood boostrap," Journal of the Royal Statistical Society (B), 56, 3-48. Satomura, Takuya, Jaehwan Kim, and Greg M Allenby (2011), "Multiple-constraint choice models with corner and interior solutions," Marketing Science, 30 (3), 481-490.
Seetharaman, P. B. (2003), "Probabilistic versus Random Utility Models of State Dependence: An Empirical Comparison," International Journal of Research in Marketing, 20 (1), 87-96.

(2004), "Modeling Multiple Sources of State Dependence in Random Utility Models: A Distributed Lag Approach," Marketing Science, 23 (2), 263-271.

Spiegelhalter, David J, Nicola G Best, Bradley P Carlin, and Angelika Van Der Linde (2002), "Bayesian measures of model complexity and fit," Journal of the Royal Statistical Society (B), 64 (4), 583-639.

Wertenbroch, Klaus (1998), "Consumption selfcontrol by rationing purchase quantities of virtue and vice," Marketing science, 17 (4), 317-337. 